\title{
Fontes de variação da produção e composição de leite em vacas Holandesa, Jersey e Girolando
}

\author{
Ludovico, A. ${ }^{\circledR} ;$ Trentin, M. ${ }^{1}$ e Rêgo, F.C.A. ${ }^{2}$
}

Universidade Pitágoras UNOPAR. Campus Piza. Londrina, PR. Brasil.

2Universidade Pitágoras UNOPAR. Campus Arapongas. Arapongas, PR. Brasil.

\section{PALAVRAS CHAVE ADICIONAIS}

Raça.

Células somáticas.

Estresse térmico.

Perdas.

THI.

\section{RESUMO}

Este estudo teve o objetivo de quantificar os efeitos do grupo genético, estresse térmico e a contagem de células somáticas (ECS) sobre a produção de leite de vacas das raças Holandesa, Jersey e genótipos da raça Girolando, em clima subtropical. Foram utilizados 14181 registros de controle leiteiro mensal das raças Girolando, Jersey e Holandesa, durante 7 anos. As vacas foram mantidas em pastagens, com suplementação alimentar e acesso à sombra. Dados de estação meteorológica foram utilizados para a determinação do Índice de Temperatura e Umidade (THI). Ano, ordem da lactação, período de lactação, THI e ECS foram fixados como covariáveis. A raça Holandesa obteve maior produtividade, exceto de gordura. Na raça Girolando, a produção de leite e lactose não diferiu da raça Jersey, sendo os demais parâmetros de produção inferiores a esta raça. As concentrações de componentes do leite (\%) foram maiores no leite da raça Jersey, exceto o teor de lactose. A raça Holandesa apresentou os menores teores de componentes do leite, exceto de lactose. O aumento de ECS resultou em diminuição da produção de leite que totalizou 26,3; 35,43 e 28,25\% nas raças Girolando, Jersey e Holandesa, respectivamente. A elevação do THI teve maiores efeitos na raça Holandesa, na qual o aumento do THI diminuiu $12,4 \%$ da concentração de gordura e 5,5\% de sólidos totais no leite. Conclui-se que a maior produtividade foi obtida com a raça Holandesa e maior qualidade com a raça Jersey. ECS acima de um diminui linearmente a produção de leite em todas as raça. Raças com maior proporção de genes da raça Holandesa são mais susceptíveis ao estresse térmico.

\section{Sources of variation of dairy production and milk composition in Holstein cows, Jersey and Girolando}

\section{SUMMARY}

\section{ADDITIONAL KEYWORDS}

Breed.

Somatic cell count.

Heat stress.

Losses.

TH.

\section{INFORMATION}

\section{Cronología del artículo.}

Recibido/Received: 16.07.2018

Aceptado/Accepted: 18.11 .2018

On-line: 07.04 .2019

Correspondencia a los autores/Contact e-mail:

agostinho@rocketmail.com
The aim of this study was to quantify the effects of the genetic group, heat stress and somatic cell count (SCS) on the milk production and composition of Holstein, Jersey and Girolando genotypes cows in subtropical climates. Were used 14181 milk test-day records from a seven years period in a commercial farm. Cows were kept on pastures, with feed supplementation and shade access. Weather station data was used to determine the temperature and humidity index (THI). Year, lactation order, lactation period, THI and SCS as fixed covariate. The Holstein breed obtained higher productivity, except fat. In the Girolando breed, the production of milk and lactose did not differ from the Jersey breed, and the other parameters of production were lower than this breed. Concentrations of milk components were higher in Jersey milk, except for lactose content. The Holstein breed showed the lowest milk component contents except lactose. The increasing of SCS resulted in a decreasing of milk production, which totaled $26.3 ; 35.43$ and $28.25 \%$ in the Girolando, Jersey and Holstein breeds, respectively. The increasing of THI had greater effects on the Holstein breed, in which the THI above 82 decreased $12.4 \%$ of fat concentration and $5.5 \%$ of total solids in milk. In conclusion, higher productivity was obtained with the Holstein and higher milk quality with the Jersey breed. SCS increasing above one unit decrease linearly milk yield in all breeds. Genotypes with a higher proportion of Holstein breed genes are more susceptible to heat stress effects.

\section{INTRODUÇÃO}

O desempenho técnico e econômico da exploração leiteira depende da interação de vários fatores do sistema de produção, incluindo o ambiente, o grupo genético e sanidade dos animais. No Brasil, prevalece o clima tropical, que favorece a produção de forragens do grupo C4, com alta eficiência fotossintética (Raven, Evert \& Eichhorn 2001), beneficiando a produção de leite em pastagens. Porém, as maiores produtividades de leite são alcançadas por vacas de raças europeias, como a Holandesa, que são mais susceptíveis ao estres- 
se térmico que as raças zebuínas, e a raça Gir (Baccari Jr 2001). Em consequência deste fato, tem-se buscado a produção de leite com outras raças, consideradas mais resistentes, ou os cruzamentos de raças zebuínas com raças europeias, do qual provem a raça Girolando (Madalena 2001). Estes animais diferem no seu potencial produtivo e resistência as intempéries do ambiente, tal como alta temperatura e resistência a patógenos, (Hansen 2004; Bernman 2012; Stumpf 2016) produzindo aproximadamente $80 \%$ do leite no Brasil (ABCG Associação Brasileira de Criadores de Girolando n.d.).

No metabolismo destinado a síntese de leite ocorre liberação de calor proporcional a produtividade das vacas. Devido a dificuldade em dissipar calor corporal das vacas, aumenta-se as exigências nutricionais para manutenção, diminui o consumo de alimentos, a ruminação, a absorção de nutrientes, e altera os níveis plasmáticos de somatotropina, tiroxina e glicorticoides (West 2003). Estas alterações resultam em aumento da susceptibilidade às infecções, diminuição da produção e alterações na composição do leite (Bernabucci et al. 2010; Bernabucci et al. 2014).

A mastite é uma reação inflamatória da glândula mamária às agressões, principalmente bacterianas, pode apresentar-se na forma subclínica, que é muito frequente em vacas leiteiras e afeta a produtividade e qualidade do leite, com grandes impactos no desempenho da exploração (Müller 2000). A contagem de células somáticas no leite é um indicador do grau de sanidade da glândula mamária, sendo, inclusive, utilizado pelo Ministério da Agricultura como um dos critérios para definir qualidade sanitária do leite (Brasil, Ministério da Agricultura Pecuária e Abastecimento (MAPA) 2011).

O presente trabalho de pesquisa objetivou avaliar a produtividade e a qualidade do leite de vacas de diferentes genótipos, mantidas em um mesmo ambiente, considerando os efeitos da contagem de células somáticas e estresse térmico.

\section{MATERIAL E MÉTODOS}

Foram utilizados 14.181 registros do controle leiteiro mensal realizado pela Associação Paranaense dos Criadores de Bovinos da Raça Holandesa (APCBRH), de um rebanho comercial em propriedade localizada município de Tamarana, região norte do Paraná, longitude $51^{\circ} 04^{\prime}$ 07" W, latitude $23^{\circ} 49^{\prime} 07^{\prime \prime}$ S, $791 \mathrm{~m}$ de altitude, clima classificado como subtropical, segundo Köppen (1948).

O rebanho foi composto de vacas das raças Holandesa, Jersey e Girolando composto por diferentes genótipos, mantidas em pastagens de grama estrela (Cynodon sp), com acesso à sombra e suplementadas com silagem de milho e ração concentrada oferecida em cocho coberto, em quantidade e composição visando atender as exigências nutricionais, conforme NRC (2001). O manejo dos animais e da ordenha foi semelhante para todas as raças.

Os dados foram coletados no período de janeiro de 2006 a julho de 2013, no qual a produção de leite foi determinada através de pesagem e a composição através de análise de amostras coletadas em duas ordenhas diárias de todas as vacas. As amostras de leite foram acondicionadas em recipientes plásticos de $70 \mathrm{~mL}$ com conservante
Bronopol® (2-bromo 2-nitropropano 1,3-diol), conforme Horst (2008) e Horst (2010), e encaminhadas ao Laboratório Centralizado da APCBRH para avaliação dos teores de gordura, proteína e lactose através de leitura de absorção infravermelha em equipamento automatizado Bentley 2000®, contagem de células somáticas (CCS) em equipamento com citometria de fluxo Somacount $500 \AA$ (Bentley Intruments). O teor de sólidos não gordurosos foi determinado através da subtração do teor de gordura do teor de sólidos totais.

Para garantir a consistência das informações, eliminaram-se observações de teores de proteína, gordura e lactose acima e abaixo de dois e meio desvios-padrão em relação à média destes componentes. Para obter-se a normalidade da distribuição da CCS no leite foi feito transformação para uma escala logarítmica em escore de contagem de células somáticas (ECS), com base no procedimento desenvolvido por Shook (1982): ECS = log2 $(\mathrm{CCS} / 100)+3$. Os valores obtidos foram arredondados até seu valor inteiro mais próximo.

O período de lactação foi codificado conforme a ordem do controle leiteiro na lactação, o qual foi realizado mensalmente. $\mathrm{O}$ primeiro controle leiteiro ocorreu, em média, no $27^{\circ}$ dia de lactação.

Os efeitos do clima foram avaliados através do Índice de Temperatura e Umidade (THI) utilizando dados coletados pelo Sistema Meteorológico do Paraná - Simepar, em estação meteorológica $41 \mathrm{~km}$ distante de propriedade, altitude $746 \mathrm{~m}$. Para cálculo do THI foi utilizado a seguinte equação de Thom (1959), modificado por NOOA (1976): THI = $(0,8 \times \mathrm{T})+(\mathrm{UR} / 100) \times(\mathrm{T}-14,3)+46,3$; onde Té a temperatura do ar em termômetro de bulbo seco em ${ }^{\circ} \mathrm{C}$ e UR é a umidade relativa do ar. Os valores de THI utilizados correspondem à média de três dias anteriores de cada controle leiteiro (Bernabucci et al. 2014; West, 2003) e foram codificados de acordo com a classificação de Du Preez et al. (1990), sendo 1= normal (até 70), 2 = alerta (71 a 78) e 3 = perigo (79 a 82) e 4 = emergência (acima de 82).

Os dados foram analisados utilizando o programa Statistica, versão 13.1 (STATSOFT, 2015), através de estatística descritiva, análise de variância, correlação e regressão. Os efeitos de raça foram analisados no módulo GLM, através de análise de variância e as médias comparadas através de teste de Tukey com 5\% de significância. Os efeitos do ECS sobre a produção e composição de leite foram analisados através de análise de regressão, utilizando-se o módulo GRM. Foi utilizado o seguinte modelo para determinação dos efeitos do ECS sobre a composição do leite:

Yijklmn $=\mu+\mathrm{ANO} i+\mathrm{LAC} j+\mathrm{CON} k+\mathrm{THI} l+\mathrm{PRO}-$ $\mathrm{D} m+\mathrm{ECS} n+$ eijklmn

Onde: Yijkl = valor observado de teor do componente do leite: $\mu=$ média geral: $\mathrm{ANO} i=$ efeito fixo do ano $i(i$ $=2006, . . ., 2013):$ LAC $j$ = efeito fixo da ordem da lactação $j(j=1, \ldots, 9)$ : CONk = efeito fixo da ordem do controle leiteiro na lactação $k(k=1, \ldots, 17)$ : THIl: efeito fixo do Índice de Temperatura e Umidade $l(l=1,2,3)$ : PRODm: efeito fixo da produção de leite $m(m=1,0 ; . .42,0)$ : ECSn: efeito linear do escore de contagem de células somáticas $n(n=1, \ldots, 9)$ e eijklmn = erro aleatório associado a cada observação. Para determinação dos efeitos do THI sobre a 
Tabela I. Número total de vacas, registros de controle leiteiro e médias de características produtivas das vacas dos diferentes grupos genéticos, no período de janeiro de 2006 a março de 2013 (Number of cows, number of milk test-day records and means of productive characteristics of different breeds and Girolando genotypes cows, in a subtropical climate, in 2006-213 period).

\begin{tabular}{|c|c|c|c|c|c|c|c|c|}
\hline \multirow[b]{2}{*}{ Parâmetros } & \multicolumn{3}{|c|}{ Raças $^{1,3}$} & \multicolumn{3}{|c|}{ Genótipos Girolando } & \multicolumn{2}{|c|}{ Rebanho } \\
\hline & G & $\mathrm{J}$ & $\mathrm{H}$ & $1 / 2 \mathrm{HG}$ & $5 / 8 \mathrm{HG}$ & $3 / 4 \mathrm{HG}$ & Média & $\mathrm{DP}^{2}$ \\
\hline Número total de vacas & 493 & 301 & 329 & 95 & 168 & 68 & - & - \\
\hline Número de registros & 6.882 & 3.854 & 3.445 & 987 & 2006 & 812 & - & - \\
\hline Dias em lactação & $147,8 c$ & $161,47^{\mathrm{b}}$ & $168,31^{a}$ & 143,83 & 150,65 & 154,15 & 155,94 & 94,86 \\
\hline Idade, anos & $5,45 c$ & $6,03^{a}$ & $5,69^{b}$ & $6,22^{A}$ & $5,08^{B}$ & $5,31^{\mathrm{B}}$ & 5,67 & 2,32 \\
\hline Número de lactações & $1,87 \mathrm{c}$ & $3,15^{a}$ & $2,40^{\mathrm{b}}$ & $2,17^{A}$ & $1,88^{\mathrm{B}}$ & $1,85^{\mathrm{B}}$ & 2.35 & 1,58 \\
\hline Controles na lactação & $4,99^{b}$ & $5,73^{a}$ & $5,77^{a}$ & 5,00 & 5,14 & 5,31 & 5,36 & 3,15 \\
\hline Persistência, \% & $92,42^{b}$ & $95,96^{a}$ & $93,42^{b}$ & 92,39 & 92,23 & 95,23 & 93,64 & 31,62 \\
\hline
\end{tabular}

composição do leite, o modelo acima foi modificado, sendo considerado o efeito aleatório de THI e efeito fixo de ECS. Para determinação do efeito do ECS ou THI sobre a produção de leite e seus constituintes foi excluído do modelo acima o efeito fixo da produção de leite.

\section{RESULTADOS E DISCUSSÃO}

Os parâmetros relacionados à produção das vacas são demonstrados na Tabela I. As médias de idade e o número de lactações foram menores na raça Girolando devido a um maior número de primíparas e maior taxa de descarte desta raça no rebanho. A fazenda tinha rebanho da raça Holandesa e Jersey estabilizados e buscava aumentar o rebanho da raça Girolando.

Uma característica das raças zebuínas é o período curto de lactação (Freitas et al. 2001), o que pode ser verificado através da persistência da lactação, em que a vacas Jersey apresentaram maior valor. Os genótipos Girolando não diferiram em persistência, embora tenham apresentado valores numericamente decrescentes conforme o aumento da proporção de genes da raça Gir.

De uma forma geral, a produção de leite e seus componentes (Tabela II) na raça Holandesa foram

Tabela II. Médias de produção e concentração de componentes do leite conforme o grupo genético de um rebanho leiteiro, no período de janeiro de 2006 a marco de 2013 (Least square means of milk production and composition according the breed and Girolando genotypes of cows of a dairy herd, in a subtropical climate, in 2006-213 period).

\begin{tabular}{|c|c|c|c|c|c|c|c|c|}
\hline & \multicolumn{3}{|c|}{$\operatorname{Raças~}^{1,8}$} & \multicolumn{3}{|c|}{ Genótipos Girolando 2, 8} & \multicolumn{2}{|c|}{ Rebanho } \\
\hline & $\begin{array}{c}G \\
(n=6.882)\end{array}$ & $\begin{array}{c}\mathrm{J} \\
(\mathrm{n}=3.854)\end{array}$ & $\begin{array}{c}\mathrm{H} \\
(\mathrm{n}=3.445)\end{array}$ & $\begin{array}{c}1 / 2 \mathrm{HG} \\
(n=987)\end{array}$ & $\begin{array}{c}5 / 8 \mathrm{HG} \\
(n=2.006)\end{array}$ & $\begin{array}{l}3 / 4 \mathrm{HG} \\
(n=812)\end{array}$ & Média & $\mathrm{DP}^{3}$ \\
\hline \multicolumn{9}{|c|}{ Produção (kg/vaca/dia) } \\
\hline Leite & $14,82^{\mathrm{b}}$ & $15,07^{b}$ & $18,96^{\mathrm{a}}$ & 15,27 & 14,91 & 14,61 & 15,74 & 5,86 \\
\hline Proteína & $0,49^{c}$ & $0,56^{b}$ & $0,59^{a}$ & $0,50^{\mathrm{A}}$ & $0,49^{A B}$ & $0,47^{\mathrm{B}}$ & 0,53 & 0,18 \\
\hline Gordura & $0,56^{c}$ & $0,66^{a}$ & $0,64^{b}$ & $0,58^{A}$ & $0,57^{A B}$ & $0,54^{\mathrm{B}}$ & 0,60 & 0,24 \\
\hline Lactose & $0,69^{b}$ & $0,69^{b}$ & $0,88^{a}$ & 0,69 & 0,68 & 0,67 & 0,73 & 0,28 \\
\hline Sólidos totais & $1,87^{c}$ & $2,07^{\mathrm{b}}$ & $2,28^{a}$ & 1,91 & 1,83 & 1,88 & 2,01 & 0,71 \\
\hline \multicolumn{9}{|c|}{ Composição do leite (\%) } \\
\hline Proteína & $3,32^{b}$ & $3,74^{a}$ & $3,14^{c}$ & 3,31 & 3,25 & 3,29 & 3,40 & 0,42 \\
\hline Gordura & $3,78^{b}$ & $4,36^{a}$ & $3,40^{c}$ & $3,85^{\mathrm{AB}}$ & $3,87^{\mathrm{A}}$ & $3,75^{\mathrm{B}}$ & 3,87 & 0,94 \\
\hline Lactose & $4,52^{b}$ & $4,47^{c}$ & $4,56^{a}$ & $4,47^{\mathrm{B}}$ & $4,50^{\mathrm{B}}$ & $4,57^{\mathrm{A}}$ & 4,51 & 0,29 \\
\hline Sólidos totais & $12,56^{b}$ & $13,57^{a}$ & $12,00^{c}$ & 12,58 & 12,56 & 12,64 & 12,74 & 1,24 \\
\hline $\mathrm{SNG}^{4}$ & $8,78^{b}$ & $9,20^{a}$ & $8,61^{c}$ & $8,73^{\mathrm{B}}$ & $8,78^{\mathrm{AB}}$ & $8,81^{A}$ & 8,86 & 0,54 \\
\hline Relação G:P5 & $1,14^{b}$ & $1,17^{a}$ & $1,09^{c}$ & 1,16 & 1,16 & 1,14 & 1,14 & 0,24 \\
\hline $\mathrm{CCS}, \mathrm{mil} / \mathrm{mL}^{6}$ & 409,62 & 368,97 & 386,08 & 463,40 & 478,72 & 391,04 & 393,31 & 713,00 \\
\hline $\mathrm{SCS}^{7}$ & $3,54^{\mathrm{a}}$ & $3,56^{a}$ & $3,22^{b}$ & 3,31 & 3,27 & 3,11 & 3,48 & 2,09 \\
\hline
\end{tabular}

${ }^{1}$ raças G: Girolando; H: Holandesa; J: Jersey; ${ }^{2}$ fração de genes da raça Holandesa; ${ }^{3}$ desvio padrão; ${ }^{4}$ sólidos não gordurosos; ${ }^{5}$ relação gordura:proteína; ${ }^{6}$ contagem de células somáticas no leite; ${ }^{7}$ escore de contagem de células somáticas no leite; ${ }^{8}$ médias com letras minúsculas ou maiúscula na mesma linha diferem no teste de Tukey ao nível de $5 \%$ de significância em Raças e Genótipos Girolando, respectivamente. 

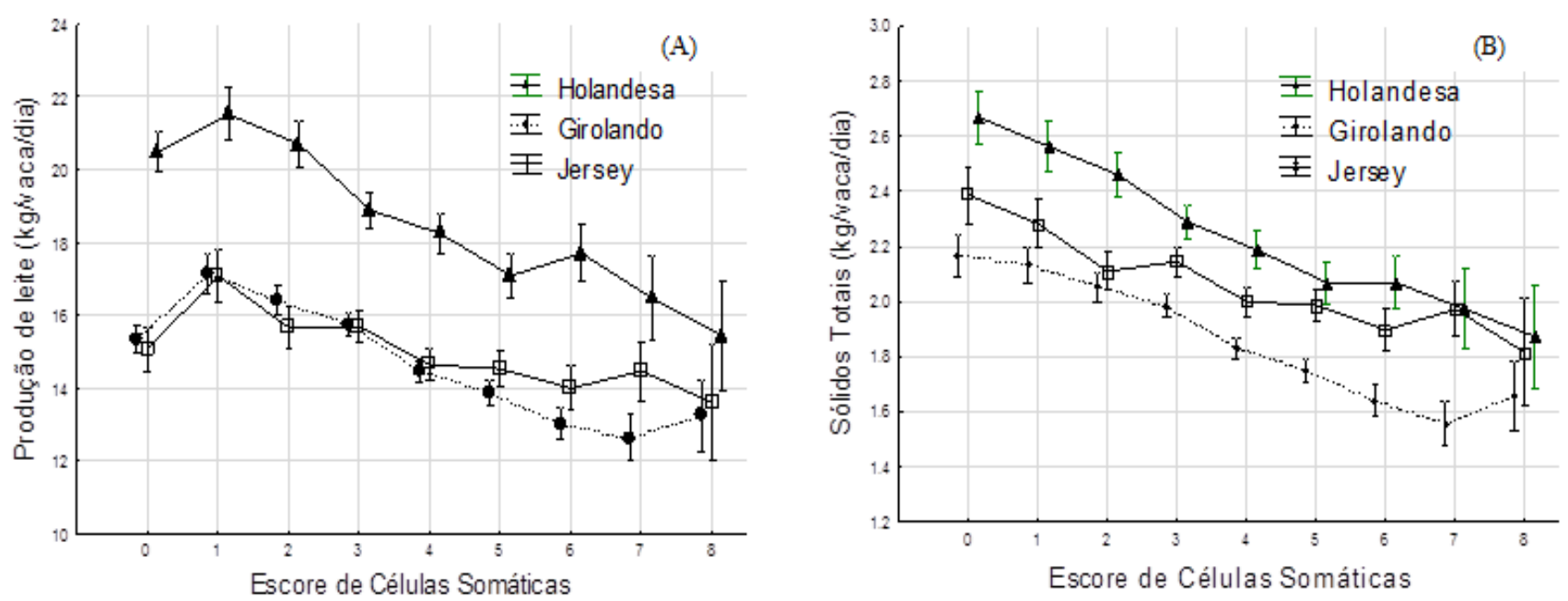

Figura 1. Médias de quadrado mínimo (pontos) e intervalo de confiança de $95 \%$ (barras) de produção de leite (figura A) e sólidos totais (figura B) conforme o escore de células somáticas no leite de vacas Girolando, Jersey e Holandesa (Least square means (point) and $95 \%$ confidence interval (bars) of milk (figure A) and total milk solids (figure B) production according somatic cell score in milk of Girolando, Jersey and Holstein cows).

superiores às demais, exceto a produção de gordura que foi superior na raça Jersey. A raça Girolando teve a menor produção de proteína, gordura e sólidos totais.

$\mathrm{Na}$ análise comparativa entre os genótipos Girolando (Tabela II), a produção de gordura e proteína de vacas com maior percentual de genes da raça Holandesa $(3 / 4 \mathrm{HG})$ foi inferior às demais. Os resultados de produção de leite encontrados nos genótipos Girolando são superiores ao encontrado por Cayo (2013) que, analisando 11.177 registros de ordenhas do Programa de Melhoramento Genético da Raça Girolando, sob gerenciamento da Embrapa Gado de Leite, observou produção corrigida para 305 dias de lactação de $3.900 \pm 1.845 ; 3.449 \pm 17,29$ e $4.246 \pm 18,26 \mathrm{~kg} /$ leite nos genótipos 1/2HG, 5/8HG e 3/4HG, respectivamente.
A concentração de componentes do leite (Tabela II), de uma forma geral, foi maior na raça Jersey e os menores teores na Holandesa, exceto o teor de lactose, que foi maior nesta raça. A raça Girolando apresentou valores intermediários. Nos genótipos Girolando, o teor de lactose no leite foi crescente conforme o aumento de genes da raça Holandesa. Este fato resultou, também, em efeito similar na concentração de sólidos não gordurosos.

A contagem de células somáticas do leite não diferiu entre as raças e genótipos Girolando (Tabela III). As médias observadas estão dentro do limite estabelecido para até junho/2014 pela legislação (Brasil, Ministério da Agricultura Pecuária e Abastecimento (MAPA) 2011), que estabelecia 480 mil células $/ \mathrm{mL}$ de leite. Entretanto, a contagem de células somática
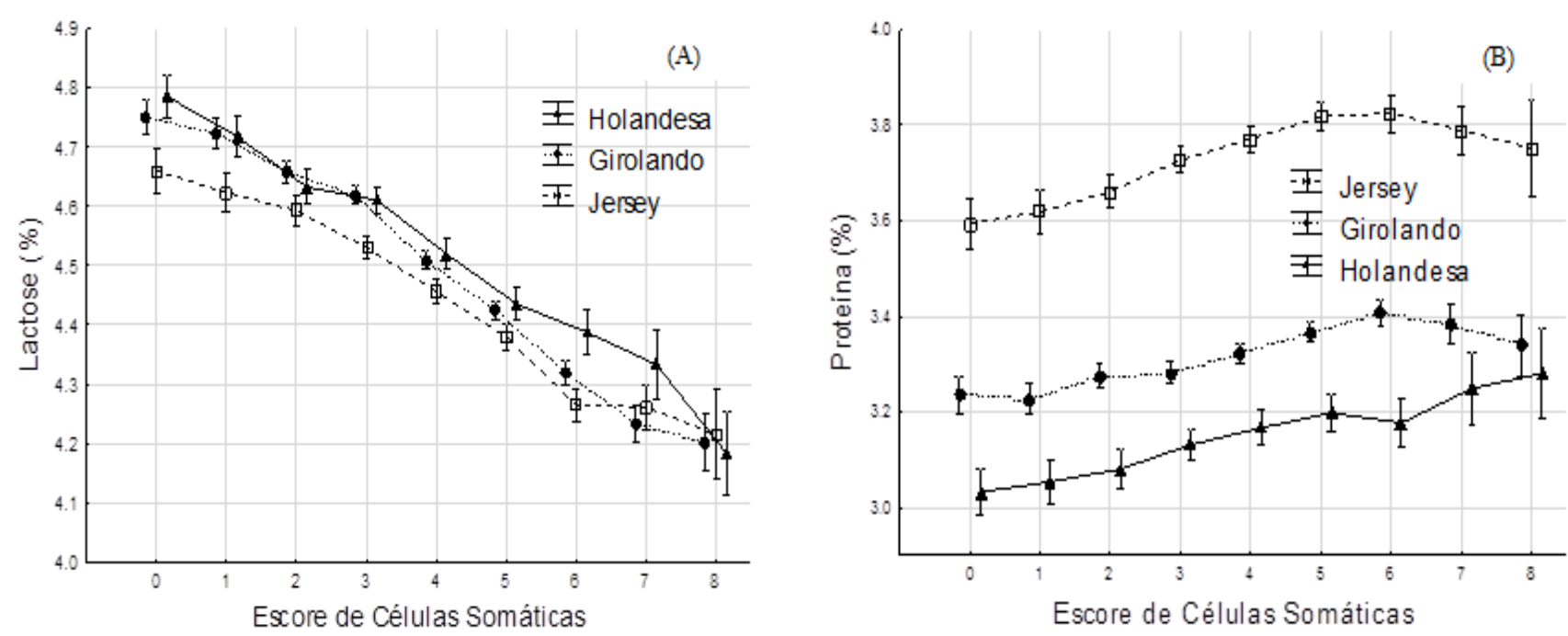

Figura 2. Médias de quadrado mínimo de teores de lactose (figura A) e proteína (figura B) conforme o escore de células somáticas no leite de vacas Girolando, Jersey e Holandesa (Least square means (point) and 95\% confidence interval (bars) of lactose (figure A) and protein (figure B) content of milk according somatic cell score in milk of Girolando, Jersey and Holstein cows). 
Tabela III. Mínimos e máximos da contagem de células somáticas (CCS/1000 células/mL), médias de produção diária de leite (kg/vaca/dia) e o valor relativo $(\%)$ da produção com os diferentes escores de células somáticas (ECS) no leite nas raças Girolando $(n=5841)$, Jersey $(n=3192)$ e Holandesa $(n=2331)$ (Minimum and maximum of somatic cells count $(\mathrm{CCS} / 1000 \mathrm{cells} / \mathrm{mL})$, least square means of milk production $(\mathrm{kg} / \mathrm{cow} /$ day) and relative production value (\%) for different somatic cell score (ECS) of milk from Girolando, Jersey and Holstein cows).

\begin{tabular}{|c|c|c|c|c|c|c|c|c|c|}
\hline \multicolumn{10}{|c|}{ Raças } \\
\hline & & \multicolumn{2}{|c|}{ Girolando } & \multicolumn{2}{|c|}{ Jersey } & \multicolumn{2}{|c|}{ Holandesa } & \multicolumn{2}{|c|}{ Rebanho } \\
\hline ECS & CCS & $\mathrm{Kg}$ & $\%$ & $\mathrm{Kg}$ & $\%$ & $\mathrm{Kg}$ & $\%$ & $\mathrm{Kg}$ & $\%$ \\
\hline 0 & $1-17$ & 15.35 & 89.58 & 15.06 & 88.11 & 20.50 & 95.28 & 16.60 & 90.98 \\
\hline 1 & $18-35$ & 17.14 & 100.00 & 17.09 & 100.00 & 21.51 & 100.00 & 18.25 & 100.00 \\
\hline 2 & $36-70$ & 16.42 & 95.80 & 15.67 & 91.68 & 20.70 & 96.20 & 17.13 & 93.85 \\
\hline 3 & $71-141$ & 15.75 & 91.91 & 15.69 & 91.83 & 18.89 & 87.81 & 16.45 & 90.13 \\
\hline 4 & $142-282$ & 14.44 & 84.29 & 14.64 & 85.68 & 18.24 & 84.78 & 15.16 & 83.08 \\
\hline 5 & $183-565$ & 13.88 & 81.01 & 14.53 & 85.04 & 17.09 & 79.44 & 14.62 & 80.09 \\
\hline 6 & $566-1131$ & 13.04 & 76.08 & 14.00 & 81.92 & 17.71 & 82.30 & 14.12 & 77.36 \\
\hline 7 & $1132-2260$ & 12.63 & 73.69 & 14.47 & 84.68 & 16.47 & 76.54 & 13.81 & 75.70 \\
\hline 8 & $2264-4510$ & 13.24 & 77.26 & 13.61 & 79.64 & 15.44 & 71.75 & 13.84 & 75.84 \\
\hline 9 & $4552-8962$ & 13,38 & 78.09 & 11,03 & 64.57 & 15,59 & 72.46 & 13.78 & 75.49 \\
\hline
\end{tabular}

resultou em perdas $(\mathrm{p}<0,05)$ que totalizaram até 26,31 ; 35,43 e $28,25 \%$ da produção diária nas raças Girolando, Jersey e Holandesa, respectivamente (Tabela III).

Considerando-se as perdas a partir do ECS 1 e o número de ordenhas em cada escore, conclui-se que as perdas no rebanho totalizaram $18,64 \%$ da produção de leite, devido a esta causa de variação.

Na figura 1, observa-se que o comportamento da curva de decréscimo de produção de leite (figura 1-A) e sólidos totais (figura 1-B) com o aumento do ECS foi semelhante nas três raças. O efeito do número de células somáticas no leite sobre a produção de leite foi avaliado considerando-se até o ECS 8, devido ao baixo número de dados com o ECS 9. As perdas na produção de sólidos totais alcançaram 20,76\% na raça Girolando; $26,52 \%$ na Jersey e $26,61 \%$ na Holandesa, com o SCS 8 , comparado com SCS 0.

A concentração de lactose diminuiu linearmente com o aumento de células somáticas no leite a partir do ECS 0 até o ECS 8 (figura 2-A). As vacas com ECS 8 apresentaram diminuição de 10,$64 ; 8,81$ e $10,54 \%$ da concentração de lactose no leite nas raças Girolando, Jersey e Holandesa, respectivamente, comparado com ECS 0. Diminuição do teor de lactose com aumento da CCS é descrito pela maioria dos pesquisadores (Geary et al. 2013). A reação inflamatória provocada por patógenos na glândula mamária provoca danos celulares que resultam em diminuição da síntese e vazamento de lactose dos alvéolos para o sangue, devido aumento da permeabilidade da barreira sangue-leite (Harmon 1994; Shuster et al. 1991).

O teor de lactose, o qual é o principal determinante do volume de leite, através de um mecanismo de gradiente osmótico (Linzell \& Peaker 1971). Assim, a diminuição observada na concentração de lactose com o aumento de ECS pode explicar a diminuição na produção diária de leite das vacas com esta causa de variação.
Ao contrário da lactose, o teor de proteínas no leite (figura 2-B), de uma forma geral, aumentou até 5,04; 6,06 e $7,56 \%$ no leite das raças Girolando, Jersey e Holandesa, respectivamente, comparado com a concentração no ECS 0. As raças Girolando e Jersey apresentaram diminuição a partir do ECS 6.

As proteínas do leite podem ser provenientes do soro sanguíneo (ex. imunoglobulinas, soroalbuminas) ou sintetizadas na glândula mamária (ex. caseína, lactoalbumina, lactoglobulina). O teor de caseína no leite pode ser diminuído pela atividade proteolítica da plasmina proveniente do sangue ou pela diminuição da síntese provocada pelos danos celulares, porém, os danos da barreira sangue-leite podem aumentar o influxo de proteínas do soro para dentro do alvéolo (Auldist et al. 1995; Kitchen 1981; Ng-Kwai-Hang et al. 1982). Este último mecanismo pode explicar o aumento da concentração de proteínas no leite conforme o aumento do ECS no presente estudo.

O ECS resultou em efeito menos definido sobre o teor de gordura que dos demais componentes, porém igual nas diferentes raças. Os teores de gordura se elevaram até o ECS 5 e, a partir deste, diminuíram com o aumento do ECS. Segundo Azzara e Dimmick (1985), o aumento da contagem de células somáticas provoca diminuição da síntese de gordura devido aos danos no epitélio secretor e atividade lipolítica ou proteolítica de enzimas leucocitárias. Porém, a forte redução da produção de leite, pode resultar em aumento da concentração de gordura, o que pode explicar os resultados até o ECS 5, a partir do qual ocorreu diminuição da concentração de gordura.

A figura 3 demonstra a distribuição dos valores do THI nos diferentes meses no período estudado. Segundo a classificação de Du Preez et al. (1990), o THI superior a 82 é classificado como "emergência" e esta condição ocorreu em $12 \%$ dos registros dos controles leiteiros, enquanto THI entre 79 a 82, classificado como "perigo" ocorreu em $32 \%$, entre 71 e 78 , classificado como "alerta", ocorreu em $36 \%$, e o restante (20\%) dos 


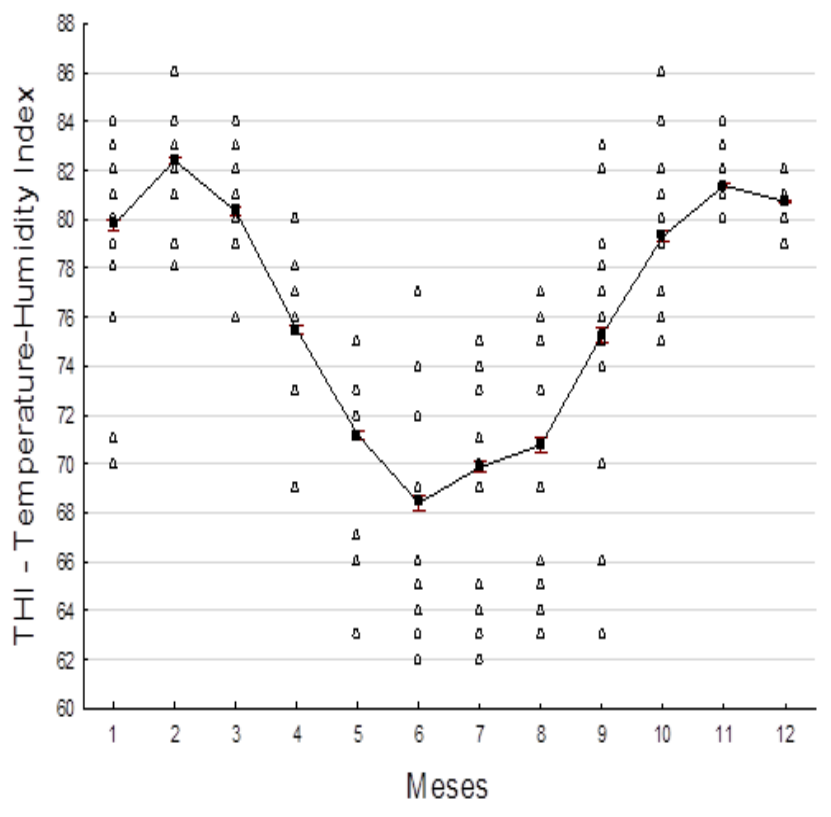

Figura 3. Médias (pontos na linha) e valores individuais mensais de índice de temperatura e umidade (THI) no período 2006-2013, em propriedade no clima subtropical (Monthly means (point in line) and individual values (triangles) of THI in 20006-2013 period, in a farm in a subtropical climate). Nas raças Holandesa e Girolando, totalizando, em média, $5 \%$ de diminuição de sólidos e $2,5 \%$ de sólidos não gordurosos, quando THI foi superior a 82, comparado com THI até 70 (normal). O teor de gordura foi a variável de qualidade de leite mais afetada pelo aumento do THI. Na raça Holandesa ocorreu diminuição de $12,36 \%$ do teor de gordura, na raça Girolando, $9,25 \%$ e 4,24\% na raça Jersey, quando $\mathrm{THI}$ foi superior a 82 . Os diferentes genótipos Girolando não apresentaram diferenças na produção de leite $(\mathrm{kg} /$ vaca/dia), mas demonstram efeitos do THI na composição do leite. Os genótipos $1 / 2 \mathrm{HG}$ e $5 / 8 \mathrm{HG}$ diminuíram, em média $11 \%$ o teor de gordura e $4,5 \%$ o teor de sólidos totais no leite no THI 4 , comparado com THI 1 (figura 4). Estes resultados corroboram com resultados de Azevedo et al. (2005) que concluíram que o THI a partir do qual inicia estresse térmico é de 76,77 e 79 nas vacas com genótipos 1/2, $3 / 4$ e $7 / 8$ Holandês-Zebu, respectivamente, mantidas em pastagens com acesso a sombra e produzindo, no mínimo, $10 \mathrm{~kg}$ de leite/dia.

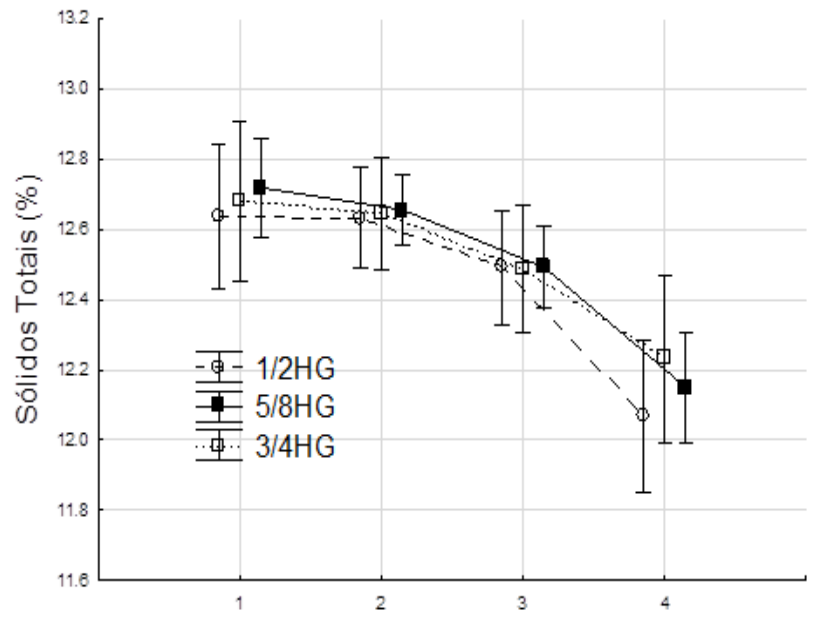

THI - Temperature-Humidity Index

Figura 4. Média de quadrados mínimos (pontos) e intervalo de confiança 95\% (barras) da concentração (\%) de sólidos totais no leite de vacas de diferentes genótipos Holandês-Gir (HG) para Ïndice de Temperatura e Umidade-THI até 70 (THI 1), de 71 a 78 (THI 2), 79 a 82 (THI 3) e superior a 82 (THI 4), no período de 2006 até 2013 (Least square means (point) and 95\% confidence interval (bars) of total solids milk content of different Holstein-Gyr (H-G) genotypes cows for THI until 70 (THI 1), from 71 to 78 (THI 2), from 79 to 82 (THI 3) and higher than 82 (THI 4), in 2006-2013 period.).

registros ocorreu com THI inferior a 71, classificado como "normal".

O aumento do THI não resultou em diferenças significativas na produção diária de leite e seus componentes $(\mathrm{kg} / \mathrm{vaca} / \mathrm{dia})$ nas diferentes raças. Porém, de uma maneira geral, o aumento do THI resultou em prejuízos sobre a composição do leite. Quando o THI foi de 79 ou mais, ocorreu diminuição no teor de sólidos totais e sólidos não gordurosos

Bernabucci et al. (2014) avaliaram a composição do leite de 25 vacas nas diferentes estações climáticas, no verão (THI médio de 75), comparado com inverno $(\mathrm{THI}<60$ ), encontraram diminuição de 5,3\% no

Tabela IV. Médias de quadro mínimo de produção de leite (kg/vaca/dia) e concentração (\%) de seus componentes em vacas Girolando, Jersey e Holandesa, conforme a classificação do índice de temperatura e umidade (THI) (Least square means of milk production (kg/cow/day) and composition (\%) of Girolando, Jersey and Holstein cows, according the THI classification).

\begin{tabular}{|c|c|c|c|c|c|c|c|c|c|c|c|c|c|c|}
\hline \multicolumn{6}{|c|}{ Girolando 1,2 } & \multicolumn{3}{|c|}{ Jersey ${ }^{1,2}$} & \multicolumn{4}{|c|}{ Holandesa ${ }^{1,2}$} & \multirow[b]{2}{*}{ Média } & \multirow[b]{2}{*}{ DP } \\
\hline Variável & 1 & 2 & 3 & 4 & 1 & 2 & 3 & 4 & 1 & 2 & 3 & 4 & & \\
\hline $\mathrm{N}$ & 1094 & 1947 & 1554 & 713 & 646 & 910 & 1014 & 267 & 385 & 788 & 613 & 189 & & \\
\hline Leite & 15.33 & 15.31 & 14.8 & 14.69 & 15.36 & 15.98 & 15.53 & 14.87 & 18.83 & 19.61 & 20.22 & 18.79 & 16.10 & 5.82 \\
\hline Lactose & $4.54^{a}$ & $4.51^{a}$ & $4.49^{b}$ & $4.43^{c}$ & $4.45^{\mathrm{a}}$ & $4.48^{a}$ & $4.46^{a}$ & $4.39^{b}$ & 4.57 & 4.55 & 4.58 & 4.50 & 4.50 & 0.34 \\
\hline Proteína & 3.31 & 3.33 & 3.31 & 3.28 & $3.72^{\mathrm{ab}}$ & $3.75^{\mathrm{a}}$ & $3.68^{\mathrm{ab}}$ & $3.70^{b}$ & $3.14^{\mathrm{ab}}$ & $3.16^{a}$ & $3.06^{b}$ & $3.03^{b}$ & 3.39 & 0.43 \\
\hline Gordura & $3.89^{a}$ & $3.82^{a}$ & $3.81^{a}$ & $3.53^{\mathrm{b}}$ & $4.48^{a}$ & $4.36^{\mathrm{ab}}$ & $4.31^{b}$ & $4.29^{b}$ & $3.56^{a}$ & $3.42^{\mathrm{ab}}$ & $3.30^{\mathrm{b}}$ & $3.12^{\mathrm{b}}$ & 3.87 & 1.01 \\
\hline $\mathrm{SNG}^{3}$ & $8.83^{a}$ & $8.79^{a b}$ & $8.74^{b}$ & $8.63^{c}$ & $9.16^{b}$ & $9.25^{\mathrm{a}}$ & $9.15^{b}$ & $9.08^{b}$ & $8.65^{a}$ & $8.65^{a}$ & $8.55^{b}$ & $8.42^{b}$ & 8.85 & 0.55 \\
\hline Sólidos & $12.72^{\mathrm{a}}$ & $12.61^{\mathrm{ab}}$ & $12.54^{\mathrm{b}}$ & $12.15^{\mathrm{c}}$ & 13.64 & 13.62 & 13.45 & 13.36 & $12.22^{\mathrm{a}}$ & $12.06^{\mathrm{a}}$ & $11.84^{b}$ & $11.55^{\mathrm{b}}$ & 12.72 & 1.31 \\
\hline
\end{tabular}

${ }^{1}$ Os números referem-se a seguinte classificação do THI: 1 = THI até $70 ; 2$ = THI de 71 a $78 ; 3=$ THI de 79 a $82 ; 4$ = THI superior a $82 ;{ }^{2}$ letras diferentes na mesma linha e raça indicam diferença significativa no teste de Tukey com $5 \%$ de significância; ${ }^{3}$ sólidos não gordurosos. 
teor de sólidos totais, 2,8\% de sólidos não gordurosos, $15,8 \%$ de gordura e $6 \%$ de proteínas. As diminuições nas concentrações de lactose e gordura com estresse térmico são atribuídas principalmente à diminuição do consumo de alimentos e a uma menor eficiência na digestão e absorção de nutrientes (Baumgard e Rhoads 2013; Kadzere et al. 2002). A diminuição dos teores de proteínas, segundo Baumgard e Rhoads (2013) e Cowle et al. (2015), resulta de uma menor disponibilidade de aminoácidos, os quais são catabolizados para síntese de glicose, através da gliconeogenese durante o estresse térmico. Han et al. (2011), observaram em estudos in vitro com células epiteliais da glândula mamária, que o estresse térmico diminuiu o nível de RNAm de proteínas do leite, e sugeriram esta causa para a diminuição do teor de proteínas no leite.

Segundo Berman (2012), a temperatura a partir da qual inicia o estresse térmico varia conforme o grau de adaptação e a produtividade de vacas. Vacas de alta produção perdem mais energia na forma de calor, o que totaliza aproximadamente $31 \%$ da energia ingerida em uma vaca de $600 \mathrm{~kg}$ de peso vivo, produzindo 40 $\mathrm{kg} /$ leite/dia com $4 \%$ de gordura. Assim, a ausência de efeitos do aumento de THI sobre a produção de leite (kg/vaca/dia) no presente estudo pode ser atribuída a baixa produtividade das vacas, aliado a adaptação das mesmas ao clima local, uma vez que foram nascidas e criadas nesta propriedade.

\section{CONCLUSÃO}

A maior produtividade diária é obtida com raça Holandesa, seguido pelas raças Jersey e a Girolando, com exceção da produção de gordura, que é maior na raça Jersey. Esta raça apresenta leite com maior concentração de constituintes químicos, exceto o teor de lactose que é maior na raça Holandesa ou nos genótipos com maior proporção desta raça.

A produção de leite e sólidos totais decresce linearmente com a elevação da SCS acima de 1 e 0, respectivamente, e totaliza $24,5 \%$ da produção de leite com SCS 9 , e $24,6 \%$ de sólidos totais com SCS 8 . O teor de lactose diminuiu, em média 10\% com a elevação do SCS até 8.

O aumento do THI até valores acima de 82 (nível 4), diminui a concentração de componentes do leite em todas a raças, mas as maiores diminuições ocorreram no leite de vacas das raças Holandesa, seguido pela raça Girolando e Jersey. A diminuição do teor de gordura totalizou $12,4 \%$ e de sólidos totais $5,5 \%$ na raça Holandesa. Nos diferentes genótipos que compõe a raça Girolando, o aumento do THI resultou em alterações semelhantes. A indústria também pode ter prejuízos com os efeitos do estresse térmico, devido diminuição da concentração de componentes do leite.

\section{AGRADECIMENTOS}

UNOPAR Pitágoras, Capes.

\section{BIBLIOGRAFIA}

ABCG - Associação Brasileira de Criadores de Girolando, Girolando - a raça mais versátil do mundo tropical, viewed 11 September
2016, <http://www.girolando.com.br/index.php?paginasSite/ girolando, 3 , pt>

Auldist, MJ, Coats, S, Rogers, GL \& McDowell, GH 1995, 'Changes in the compositional of milk form healthy and mastitic dairy cows during the lactation cycle', Australian Journal of Experimental Agriculture, vol 35, no. 4, pp. 427-436.

Azevedo, M, Pires, MFA, Saturnino, HM, Lana, AMQ, Sampaio, IBM, Monteiro, JBN \& Morato, LE 2005, 'Estimativa de níveis críticos superiores do índice de temperatura e umidade para vacas leiteiras 1/2, 3/4 e 7/8 Holandês-Zebu em lactação', Revista Brasileira de Zootecnia, vol 34, no. 6, pp. 2000-2008.

Azzara, CD \& Dimmick, PS 1985, 'Lipoprotein lipase activity of milk from cows with prolonged subclinical mastitis', Journal of Dairy Science, vol 68 , no. 12, pp. 3171-3175

Baccari Jr, F 2001, Manejo ambiental da vaca leiteira em climas quentes, UEL, Londrina.

Baumgard, LH \& Rhoads, RP 2013, 'Effects of heat stress on postasortive metabolism and energetic', Annual Review of Animal Bioscience, vol 1, no. 1, pp. 311-337.

Bernabucci, U, Biffani, S, Buggiotti, L, Vitali, A, Lacetera, N\&Nardone, A 2014, 'The effect of heat stress in Italian Holstein dairy cattle', Journal of Dairy Science, vol 97, pp. 471-486.

Bernabucci, U, Lacetera, N, Baaumgard, LH, Rhoads, RP, Ronchi, B \& Nardone, A 2010, 'Metabolic and hormonal acclimation to heat stress in domecticated ruminants', Animal, vol 4, no. 7, pp. 1167-1183.

Bernabucci, U, Lacetera, N, Baumgard, LH, Rhoads, RP, Ronchi, B \& Nardone, A 2010, 'Metabolic and hormonal acclimation to heat stress in domesticated ruminants', Animal, vol 4, no. 7, pp. 1167-1183.

Bernman, A 2012, 'From heat tolerance to heat stress relief: an evolution of notions in animal farming', in RJ Collier, CJ L (eds.), Enviromental Physology of Livestock, 1 st edn, John Wiley \& Sons, Chichester.

Brasil, Ministério da Agricultura Pecuária e Abastecimento (MAPA) 2011 , 'Instrução Normativa n ${ }^{\circ} 62$ de 29/12/201 1', Diário Oficial da União, 30 Dezembro 2011.

Cayo, AWC 2013, 'Avaliação genética da produção de leite e de características reprodutivas de bovinos da raça Girolando', Tese de Doutorado, Genética e Melhoramento, Universidade Federal de Viçosa, Viçosa.

Cowley, FC, Barber, DG, Houlihan, AV \& Poppi, DP 2015, 'Immediate and residual effects of heat stress and restricted intake on milk protein and casein composition and energy metabolism', Journal of Dairy Science, vol 98, pp. 2356-2368.

Du Preezz, JD, Giesecke, WH, Hattingh, PJ \& Eisenberg, BE 1990, 'Heat stress in dairy cattle and other livestock under Southern African conditions. II. Identification of areas of potential heat stress during summer by means of observed true and predicted temperature-humidity index values', Onderstepoort Journal of Veterinary Research, vol 57, pp. 183-187.

Freitas, MS, Durães, MC, Freitas, AF \& Barra, RB 2001, 'Comparação da produção de leite e de gordura e da duração da lactação entre cinco "graus de sangue" originados de cruzamentos entre Holandês e Gir em Minas Gerais', Arquivos Brasileiros de Medicina Veterinária e Zootecnia, vol 53, pp. 708-713.

Geary, U, Lopez-Villalobos, N, O'Brien, B, Garrick, DJ \& Shalloo, L 2013, 'Meta-analysis to investigate relationships between somatic cell count and raw milk composition, Cheddar cheese processing characteristics and cheese composition', Irish Journal of Agricultural and Food Research, vol 52, no. 2, pp. 119-133.

Han, H, Jiaqi, W, Fadi, L, Dengpan, B, Linyun, Z \& Ruiliam, C 2011 , 'Responses of cultured bovine mammary epithelial cells to heat stress', Journal of Agriculture and Biotechnology, vol 19, pp. 287-293.

Hansen, PJ 2004, 'Physiological and cellular adaptations of zebu to thermal stress', Animal Reproduction Science, vol 82, pp. 349-360.

Harmon, RJ 1994, 'Physiology of mastitis and factors affecting somatic cell counts', Journal of Dairy Science, vol 77, no. 7, pp. 2103-2112.

Horst, JA 2008, 'Manual de operações de campo', Programa de análise de rebanhos leiteiros do Paraná, APCBRH, Curitiba. 
Horst, JA 2010, 'Manual de coleta de amostras: componentes e CCS', Programa de análise de rebanhos leiteiros do Paraná, APCBRH, Curitiba.

Kadzere, CT, Murphy, MR, Silanikove, N \& Maltz, E 2002, 'Heat stress in lactating dairy cows: a review', Livestock Production Science, vol 77, no. 1, pp. 59-91.

Kitchen, BJ 1981, 'Reviews of progress of dairy science: Milk compositional changes and related diagnostic tests', Journal of Dairy Science, vol 48 , no. 1, pp. 167-188.

Köpen, W 1948, Climatologia, Gráfica Panamericana, Buenos Aires. Linzell, JL\&Peaker, M 1971, 'Mechanism of milk secretion', Physiological Reviews, vol 51, no. 3, pp. 564-597.

Madalena, FE 2001, 'A cadeia do leite no Brasil', in FE Madalena, LL Matos, EV Holanda JR (eds.), Produção de leite e sociedade, FEPMVZ, Belo Horizonte.

Müller, EE 2000, 'Profilaxia e controle da mastite', Anais do Workshop sore produção e qualidade do leite, Maringá.

Ng-Kwai-Hang, FK, Hayes, JF, Moxley, JE \& Monardes, HG 1982, 'Environmental influences on protein content and composition of bovine milk', Journal of Dairy Science, vol 65, no. 10, pp. 1993-1998.
NOAA 1976, National Weather Service United States Department of Commerce.

Raven, PH, Evert, RF \& Eichhorn, SE 2001, Biologia Vegetal, Guanabara Koogan S.A., Rio de Janeiro.

Shook, GE 1982, 'Approaches to summarizing somatic cell count which improve interpretability', Proceedings of the Annual meeting mastitis council, Arlington.

Shuster, DE, Harmon, RJ, Jackson, JA \& Hemken, RW 1991, 'Suppression of milk production during endotoxin-induced mastitis', Journal of Dairy Science, vol 74, no. 11, pp. 3763-3774.

STATSOFT 2015, Statistica (data analysis software system), Statsoft, Inc., Tulsa.

Stumpf, MT 2016, 'Respostas biológicas de bovinos das raças Holandesa e Girolando so estresse térmico', Tese de Doutorado, Universidade Federal do Rio Grande do Sul, Porto Alegre.

Thom, EC 1959, 'The discomfort index', Weatherwise, vol 12, pp. 57-59. West, JW 2003, 'Effects of heat-stress on production in dairy cattle', Journal of Dairy Science, vol 86, pp. 2131-2144. 